\title{
Synthesis and in vitro activities of a new antiviral duplex drug linking Zidovudine (AZT) and Foscarnet (PFA) via an octadecylglycerol residue
}

\author{
Schott, H ; Hamprecht, K ; Schott, S ; Schott, T C ; Schwendener, R
}

\begin{abstract}
To prepare a new antiviral duplex drug linking Zidovudine (AZT) and Foscarnet (PFA) via a lipophilic octadecylglycerol residue we condensed 1-O-4-monomethoxytrityl-3-O-octadecyl-sn-glycerol2-hydrogenphosphonate obtained from 3-O-octadecyl-sn-glycerol with AZT by the phosphonate method. The purified condensation product was de-tritylated resulting in 3 -azido-3 -deoxythymidylyl-(5 $\rightarrow 2-\mathrm{O})$ 3-O-octadecyl-sn-glycerol, followed by treatment with (ethoxycarbonyl)phosphoric dichloride. The resulting 3 -azido-3 -deoxy-thymidylyl-(5 2)-3-O-octadecyl-sn-glycerol-1-O-(ethoxycarbonyl)phosphonate was purified by preparative RP-18 column chromatography. The antiviral duplex drug 3 -azido-3 -deoxythymidylyl$(5 \rightarrow$ 2-O)-3-O-octadecyl-sn-glycerol-1-O-phosphonoformate trisodium salt (AZT-lipid-PFA) was obtained after alkaline cleavage of the phosphonoformate ethylester residue. The overall yield of the five step synthesis performed at gram scale was about 30\%. According to a supposed pathway AZT-lipid-PFA could be cleaved to yield a mixture of different antiviral compounds such as AZT, AZT-5 -monophosphate, octadecylglycerol-AZT, PFA and octadecylglycerol-PFA, possibly producing additive and/or synergistic antiviral effects. In vitro studies showed that the duplex drug exhibits antiviral activities against HIV and especially against drug-resistant strains and clinical isolates of HSV and HCMV. The E50 values of AZT-lipid-PFA against HIV ranged between 170 and $200 \mathrm{nM}$. The half-maximal inhibitory doses (IC50) against highly acyclovir (ACV)-resistant HSV isolates determined by a plaque reduction assay ranged between 1.87 and 4.59 M. Using ganciclovir (GCV)-sensitive, GCV resistant and drug cross-resistant HCMV strains the IC50-values of AZT-lipid-PFA were between 2.78 and $1.18 \mathrm{M}$. With regard to PFA, the IC50-value of AZT-lipid-PFA determined on a multi-drug-resistant HCMV strain was about 90-fold lower than that of PFA, demonstrating the superior antiviral effect of the duplex-drug.
\end{abstract}

DOI: https://doi.org/10.1016/j.bmc.2008.10.081

Posted at the Zurich Open Repository and Archive, University of Zurich ZORA URL: https://doi.org/10.5167/uzh-6776

Journal Article

Originally published at:

Schott, H; Hamprecht, K; Schott, S; Schott, T C; Schwendener, R (2009). Synthesis and in vitro activities of a new antiviral duplex drug linking Zidovudine (AZT) and Foscarnet (PFA) via an octadecylglycerol residue. Bioorganic Medicinal Chemistry, 17(1):303-310.

DOI: https://doi.org/10.1016/j.bmc.2008.10.081 


\title{
Synthesis and in vitro activities of a new antiviral duplex drug linking Zidovudine (AZT) and Foscarnet (PFA) via an octadecylglycerol residue
}

\author{
Herbert Schott $^{\mathrm{a}, *}$, Klaus Hamprecht ${ }^{\mathrm{b}}$, Sarah Schott ${ }^{\mathrm{a}}$, Timm C. Schott ${ }^{\mathrm{b}}$, Reto A. Schwendener ${ }^{\mathrm{c}}$ \\ a Institute for Organic Chemistry, University Tuebingen, Auf der Morgenstelle 18, D-72076 Tuebingen, Germany \\ ${ }^{\mathrm{b}}$ Institute of Medical Virology and Epidemiology of Viral Diseases, University Hospital of Tuebingen, D-72076 Tuebingen, Germany \\ ${ }^{\mathrm{c}}$ Institute of Molecular Cancer Research, University of Zuerich, CH-8057 Zuerich, Switzerland
}

\section{A R T I C L E I N F O}

\section{Article history:}

Received 5 July 2008

Revised 29 October 2008

Accepted 31 October 2008

Available online 5 November 2008

\section{Keywords:}

Antiviral duplex drug

Herpes simplex virus (HSV)

Human cytomegalovirus (HCMV)

Antiviral drug resistance

Hydrogenphosphonate method

\begin{abstract}
A B S T R A C T
To prepare a new antiviral duplex drug linking Zidovudine (AZT) and Foscarnet (PFA) via a lipophilic octadecylglycerol residue we condensed 1-O-4-monomethoxytrityl-3-O-octadecyl-sn-glycerol-2-hydrogenphosphonate obtained from 3-O-octadecyl-sn-glycerol with AZT by the phosphonate method. The purified condensation product was de-tritylated resulting in $3^{\prime}$-azido-3'-deoxythymidylyl-( $\left.5^{\prime} \rightarrow 2-0\right)-3-$ $O$-octadecyl-sn-glycerol, followed by treatment with (ethoxycarbonyl)phosphoric dichloride. The resulting 3'-azido-3'-deoxy-thymidylyl-(5' $\rightarrow 2$ )-3-O-octadecyl-sn-glycerol-1-O-(ethoxycarbonyl)phosphonate was purified by preparative RP-18 column chromatography. The antiviral duplex drug 3'-azido-3'-deoxythymidylyl-(5' $\rightarrow$ 2-O)-3-O-octadecyl-sn-glycerol-1-O-phosphonoformate trisodium salt (AZT-lipid-PFA) was obtained after alkaline cleavage of the phosphonoformate ethylester residue. The overall yield of the five step synthesis performed at gram scale was about $30 \%$. According to a supposed pathway AZT-lipid-PFA could be cleaved to yield a mixture of different antiviral compounds such as AZT, AZT5 '-monophosphate, octadecylglycerol-AZT, PFA and octadecylglycerol-PFA, possibly producing additive and/or synergistic antiviral effects. In vitro studies showed that the duplex drug exhibits antiviral activities against HIV and especially against drug-resistant strains and clinical isolates of HSV and HCMV. The $E_{50}$ values of AZT-lipid-PFA against HIV ranged between 170 and $200 \mathrm{nM}$. The half-maximal inhibitory doses $\left(\mathrm{IC}_{50}\right)$ against highly acyclovir ( $\mathrm{ACV}$ )-resistant $\mathrm{HSV}$ isolates determined by a plaque reduction assay ranged between 1.87 and $4.59 \mu \mathrm{M}$. Using ganciclovir (GCV)-sensitive, GCV resistant and drug cross-resistant HCMV strains the $\mathrm{IC}_{50}$-values of AZT-lipid-PFA were between 2.78 and $1.18 \mu \mathrm{M}$. With regard to PFA, the $\mathrm{IC}_{50}$-value of AZT-lipid-PFA determined on a multi-drug-resistant HCMV strain was about 90 -fold lower than that of PFA, demonstrating the superior antiviral effect of the duplex-drug.
\end{abstract}

() 2008 Elsevier Ltd. All rights reserved.

\section{Introduction}

In order to improve antiviral chemotherapy, the intense search for new effective antiviral agents is ongoing. ${ }^{1,2}$ The successful clinical application of new antiviral drugs, however, is often limited as compounds with high in vitro activity do not meet the high expectations made for drug development and licensing. An alternative to the search for new single agents inhibiting virus replication lies in the optimization of therapies by combining several well-known antiviral single drugs. Such a combination therapy scheme either aims at the simultaneous application of several single compounds, for example, the highly active antiretroviral therapy (HAART) against human immunodeficiency virus (HIV) or combination therapies containing mixtures of two (Combivir ${ }^{\mathrm{TM}}$, Epzicom ${ }^{\mathrm{TM}}$, Truva$\mathrm{da}^{\mathrm{TM}}$ ) or three (Atripla ${ }^{\mathrm{TM}}$, Trizivir ${ }^{\mathrm{TM}}$ ) active agents in one tablet. ${ }^{3,4}$ The use of such tablets simplifies the application schedule for the

\footnotetext{
* Corresponding author. Fax: +49 707165782.

E-mail address: herbert.schott@uni-tuebingen.de (H. Schott).
}

patients. However, the antiviral profiles of the single drugs in the mixtures remain unchanged.

Another promising, but not yet well-investigated possibility of antiviral combination therapy is the chemical linkage of two clinically well-characterized drugs into one molecule, a so-called duplex-drug. After uptake of a duplex drug molecule in an infected host cell, the drug can be cleaved into several metabolites, each having a different virus inhibiting profile with additive or synergistic properties. Antiviral single drugs are generally well justifiable for the synthesis of corresponding duplex molecules, if the effort for their chemical synthesis is relatively sustainable. A further important consideration is the proven efficacy and toxic profile of the single compounds. Synergistic or additive interactions of the coupled drugs ought to be considered besides possible additional activities that might result from the structure of a new duplex molecule and therefore optimize the therapeutic effect of such duplex compounds. The toxicity profile of two promising single compounds should be as distinct as possible in order to achieve reduced toxicity and optimal activity of the duplex drug 
in comparison to its parent compounds. If two drugs are only effective at significantly different therapeutic concentrations, they are not suitable for a duplex drug synthesis.

Azidothymidine (AZT) used in HIV therapy as a nucleoside reverse transcriptase inhibitor (NRTI) as well as a chain terminator. The non-nucleoside phosphonoformate (Foscarnet, PFA) used in herpesvirus (HSV) and cytomegalovirus (CMV) therapy is the drug of choice for infections with HSV that do not respond to acyclovir (ACV) and for HCMV that do not respond to ganciclovir (GCV). Both AZT and PFA fulfill several desirable properties that are required for the synthesis of a potential antiviral duplex-drug. These properties are (i) additive or synergistic antiretroviral activities, (ii) the wellknown distinct in vivo toxicity profiles, and (iii) a lack of crossresistance. ${ }^{5,6}$ Besides these aspects, PFA-resistant HIV mutants show increased susceptibility to AZT whereas the hyper-susceptible phenotype is not necessarily coupled to PFA resistance. ${ }^{7}$

PFA is a potent inhibitor of HIV-1 RT acting as pyrophosphate (PPi) analogue. ${ }^{8}$ HIV-1 RT can unblock the chain-terminating AZT by phosphorolytic transfer of the terminal residue to an acceptor substrate, which also interacts with the PPi binding site. ${ }^{9}$ Primerunblocking activity is increased in mutants of HIV-1, that are resistant to AZT and this activity is inhibited by low concentrations of PFA, which would explain the synergistic interaction between PFA and AZT. Conformational changes occur during catalytic activity by DNA and RNA polymerases. A stable complex is formed between polymerase and primer-template $(\mathrm{P} / \mathrm{T})$ upon binding of the next complementary dNTP on positions +1 and +2 on the template $(+1$ or +2 complex, respectively), or Foscarnet (Foscarnet complex), which might explain the inhibitory function of PFA on HIV RT. ${ }^{10}$ PFA shows a dual effect, specifically, at low concentrations it inhibits the removal of a terminated primer, whereas at high concentrations these compounds enhance the rescue of the terminated primer because of the PFA-dependent phosphorolysis. ${ }^{11}$

Mixtures of AZT and an excess of PFA as single entities produced a moderate synergistic inhibitory effect in vitro against HIV-1 and CMV replication and low toxicity in cell cultures as previously shown by several authors. ${ }^{6,12-14}$ The suppression of CMV replication was achieved at lower drug concentrations when AZT and PFA were combined than when the drugs were used alone. ${ }^{15}$

The first synthesized antiviral molecules linking AZT and PFA were conjugates, in which the carboxyl or phosphonyl group of PFA ester derivatives was directly covalently linked to the $5^{\prime}$-hydroxyl group of AZT or other inhibitory dideoxynucleoside analogues. ${ }^{16-19}$ The evaluated antiviral activity of these types of conjugates neither achieved substantial gains in terms of antiviral activity nor in therapeutic selectivity.

The more recently developed lipophilic AZT-PFA conjugates, in which the formic terminal of PFA was esterified with a long chain alkyl alcohols, whereas the phosphono terminal of PFA was coupled to the 5'-hydroxyl group of AZT, have the potential to act either as PFA prodrugs, AZT-prodrugs or both. The conjugates inhibit the in vitro replication of wild-type HIV-1, as well as that of PFA-resistant strain or AZT resistant clinical isolate strains, respectively. The lipophilic AZT-PFA conjugates show a noticeably higher inhibitory activity in comparison to the single drugs AZT and PFA, especially regarding resistant HIV-mutants. ${ }^{20}$ The observed antiviral activities against HIV-resistant mutants can be caused by the different inhibitory mechanisms of viral replication of AZT and PFA as described above. Based on the suggested mechanism the structure of the lipophilic AZT-PFA conjugate allows either the simultaneous release of a lipophilic PFA derivate and of AZT or alternatively, the metabolism into AZT-5'-monophosphate PFA however, is degraded by decarboxylation during formation of AZT-5'-monophosphate and is therefore lost as the second antiviral component. For the inhibitory effect of PFA a considerably higher drug concentration is needed in comparison to AZT. Under this consideration the loss of PFA by the metabolic degradation of the AZT-PFA conjugate is a structurally caused disadvantage, which can affect the activity of AZT-PFA significantly. The improved anti-HIV activity was predominantly evaluated in those AZT-PFA conjugates, and was caused especially by the AZT component. It is unknown, if these conjugates also show an anti-HSV and anti-HCMV activity, which should based on the linked PFA compound.

The present work described a new concept for the preparative conjugation of AZT with PFA. According to the new synthesis both drugs are independently linked via a glycerol lipid backbone contrast to the already synthesized AZT-PFA conjugates. Thereby, an AZT-lipid-PFA duplex drug was obtained for the first time that inhibits the viral replication of HIV, HSV as well as HCMV, as shown in well established in vitro investigations.

\section{Results and discussion}

\subsection{Synthetic chemistry}

AZT-lipid-PFA was prepared in five steps according to the synthesis scheme given in (Fig. 1) starting with 3-O-octadecyl-snglyercol (1). In the first synthesis step the free terminal hydroxyl group of 1 was blocked with the 4-monomethoxytrityl residue. After the chromatographic purification of the reaction mixture 1O-4-monomethoxytrityl-3-octadecyl-sn-glycerol (2) was obtained at $78 \%$ yield. In the second synthesis step the hydroxyl group of the protected glycerol derivative 2 was phosphonylated at $85 \%$ yield by treatment with salicylchlorophosphite followed by silica gel chromatography resulting in 1-0-4-monomethoxytrityl-3-Ooctadecyl-sn-glyerol-2-hydrogenphosphonate (3). In the following reaction 3 was condensed to the free $5^{\prime}$-hydroxyl group of $3^{\prime}$-azido3'-deoxythymidine (AZT, 4 ) which was isolated from expired capsules (Zidovudine ${ }^{\mathrm{TM}}$, Combivir ${ }^{\mathrm{TM}}$ ). ${ }^{2}$ The condensation was performed in the presence of pivaloyl chloride according to the hydrogenphosphonate method. The phosphonodiester linkage of the condensation product was immediately oxidized with iodine to yield the fully protected octadecylglycerol-AZT conjugate linking the lipophilic glycerol derivative to AZT by a phosphodiester bond. During the chromatographic fractionation of the reaction mixture on a silica column the 4-monomethoxytrityl protecting group was partially lost. The trityl-protected octadecylglycerol-AZT was separated as the main product from the de-tritylated condensation product. The isolated tritylated reaction product was treated with acetic acid to remove the 4-monomethoxytrityl protecting group. After de-protection the reaction mixture was re-chromatographed yielding the expected $\mathbf{5}$ which was identical to the de-tritylated octadecylglycerol-AZT isolated by the first chromatography of the reaction mixture. Both de-tritylated products were combined resulting in $75 \%$ yield of pure $\mathbf{5}$.

In the fourth synthesis step the free terminal hydroxyl group of 5 was reacted with (ethoxycarbonyl)phosphoric dichloride (6) in trimethylphosphate resulting in the precursor (7) of AZT-lipid-PFA, in which the formate residue was esterified with ethanol. The reaction mixture was flash chromatographed on a reverse phase column (RP-18) using water-methanol mixtures with increasing amounts of methanol as the eluent. At $20 \%$ methanolic water undesired side products and trimethylphosphate were eluted. By increasing the methanol amount the desired 3'-azido-3'-deoxythymidylyl-(5' $\rightarrow$ 2-O)-3-O-octadecyl-snglycerol-1-O-(ethoxycarbonyl)phosphonoformate (7) was eluted, followed by starting material $\mathbf{5}$ which had not reacted. The product containing fractions were pooled, concentrated and lyophilized yielding $61 \%$ of 7 as a white powder. The isolated non-reacted educt 5 was re-used for further derivatisation. Under this aspect, the PFA residue can be introduced at yields higher than $61 \%$. In the last reaction step the ethylester group of 7 was 


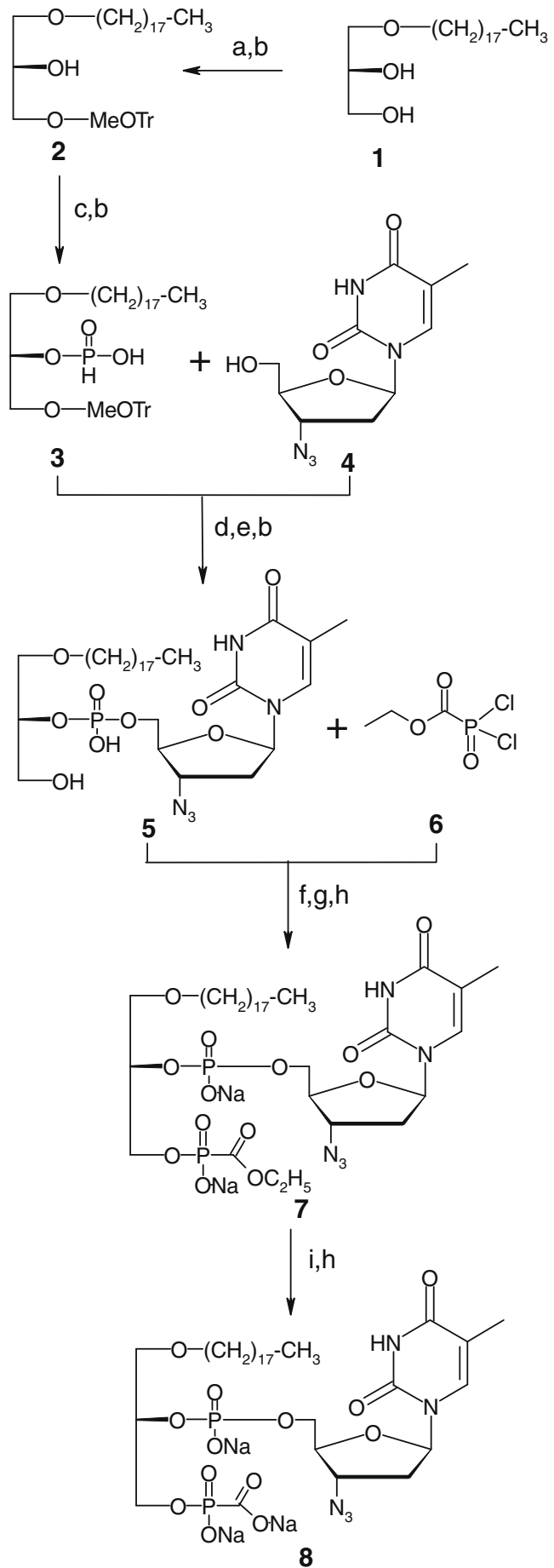

Figure 1. Synthesis of the antiviral duplex drug (3'-azido- $3^{\prime}$-deoxythymidylyl$\left(5^{\prime} \rightarrow 2-0\right)$-3-O-octadecyl-sn-glycerol-1-O-phosphonoformate) trisodium salt (8) starting from 3-octadecyl-sn-glycerol (1). The reaction steps are: (a) 4-monomethoxytrityl chloride in pyridine; (b) purification of the reaction mixture on a silica gel column; (c) salicylchlorophosphite in pyridine/dioxane; (d) pivaloyl chloride in pyridine, $7 \mathrm{~min}, 0.2 \mathrm{M}$ iodine in THF/water; (e) $80 \%$ acetic acid, room temperature; (f) trimethylphosphate, $16 \mathrm{~h}$, sodium carbonate until $\mathrm{pH} 6.5$; $(\mathrm{g})$ purification of the reaction mixture on a LiChroprep. RP-18 column; (h) lyophilisation; (i) $1 \mathrm{~N} \mathrm{NaOH}$, cation exchange $\left(\mathrm{H}^{+}\right.$-form) until $\mathrm{pH} 8.5$.

hydrolyzed under alkaline conditions resulting in the antiviral active 3'-azido-3'-deoxythymidylyl-(5' $\rightarrow$ 2-O)-3-O-octadecyl-snglycerol-1-O-phosphonoformate trisodium salt (AZT-lipid-PFA) (8) which was isolated by lyophilisation at $83 \%$ yield. The course of the syntheses and the purification steps were monitored by
TLC. The chemical structure and the analytical purity of the product were confirmed by NMR spectroscopy, high resolution mass spectroscopy and elementary analysis. Elementary analysis was within usual limits for $\mathrm{C}, \mathrm{H}$ and $\mathrm{N}$. In case of $\mathbf{5}$ and $\mathbf{8}$ the too low nitrogen analysis could be caused by the incomplete conversion of the azido group to nitrogen oxide during combustion, which was also reported before. ${ }^{20}$ The specific angles of rotation $\left([\alpha]_{\mathrm{D}}^{20}\right)$ of the glycerol derivatives $\mathbf{2}$ and $\mathbf{3}$ showed the expected negative values. The positive values $\left.\left([\alpha]_{\mathrm{D}}^{20}\right)+5.69^{\circ} ; \mathrm{c} 1.16, \mathrm{H}_{2} \mathrm{O}\right)$ of octadecylglyerol-AZT 5 was unexpected. After introduction of the PFA residue the resulting $\mathbf{7}$ and $\mathbf{8}$ showed again negative $\left([\alpha]_{D}^{20}\right)$ values.

The chemical synthesis of AZT-lipid-PFA is practicable on a preparative scale and the yield of the single reaction steps, which are not yet optimized are in the range of 70-83\%. This fulfills an important prerequisite, namely that the new antiviral duplex drug can be synthesized at sufficiently large amounts for in vivo testing and further development towards a possible therapeutic application. The successful use of the recycled AZT proves that clinically expired drugs can be used as a cheap source of valuable starting materials. The hydrolytic stability of dissolved $\mathbf{7}$ is very high and the lyophilisate can be stored at room temperature for several months without change or damage. The alkaline cleavage of the ethylester group nearly quantitatively converts $\mathbf{7}$ into AZT-lipidPFA without occurrence of side products or impurities. For this reason and because $\mathbf{7}$ can be obtained at high purity the chromatographic purification of the acid labile $\mathbf{8}$ is not necessary and a possible hydrolytic degradation during the chromatographic procedures will be avoided. In neutral environment AZT-lipidPFA is very stable because a stock solution of $8(1 \mathrm{mM})$ in water can be stored at $-20{ }^{\circ} \mathrm{C}$ more than one year without any reduction of its antiviral activity.

\subsection{Antiviral activity of AZT-lipid-PFA duplex drug}

\subsubsection{Concept of AZT-PFA duplex-drug}

We established a new structure for an AZT-lipid-PFA duplex drug, which effectively utilizes the inhibitory advantages of a covalent AZT-PFA combination, but avoids a structurally based loss of activity through the metabolic pathway of PFA. Therefore, AZT and PFA are, unlike previously described conjugates, not directly, but indirectly linked via an ether lipid molecule to a new type of AZT-lipid-PFA compound. Ether lipid conjugates may allow a major part of the drug to enter the cell due to their lipophilic residue and thus provide cells with a depot of the prodrug. In the course of the metabolic pathway lipophilic octadecylglycerol-AZT as well as octadecylglycerol-PFA prodrugs can be cleaved by enzymatic hydrolysis in addition to the formation of PFA, AZT-5'-monophosphate and AZT, respectively. Furthermore, the direct cytoplasmatic release of AZT-5'-monophosphate would not require initial phosphorylation of AZT. Ether lipids are membrane interactive, thus the lipophilic compounds could accumulate in the plasma membrane of T-lymphocytes and monocytes or macrophages. The released lipophilic prodrugs correspond to the previously described, inhibitory active alkylglycerol AZT and PFA derivatives. $^{22-25}$ Those derivatives have several advantages in comparison to the non-derivatized parent drug and are potent antiviral drugs.

\subsubsection{In vitro antiviral activities of AZT-lipid-PFA}

The anti-HIV activity of AZT-lipid-PFA was determined at the National Cancer Institute (NCI, USA). The inhibitory effects against HCMV isolates were evaluated as the half-maximal inhibitory doses $\left(\mathrm{IC}_{50}\right)$ using a modified cell-associated immediate early plaque reduction assay followed by statistical Probit evaluations in the case of HCMV. A screening plaque reduction assay (PRA) followed by Probit analysis was used for the determination of the 
$\mathrm{IC}_{50}$ of HSV. The anti-HSV effects were investigated in comparison to ACV and PFA. The evaluated antiviral potency of AZT-lipid-PFA against HCMV was compared with GCV and PFA.

\subsubsection{Antiviral activity of AZT-lipid-PFA in the HIV-1 infected CEM-SS cell line}

The anti-HIV-1 activity has been evaluated in vitro in the framework of the In Vitro Anti-AIDS Drug Discovery Program (NCI, USA). The standard procedure used in the test of the NCI for anti-HIV active compounds is designed to detect agents acting at any stage of the reproductive cycle of the virus ${ }^{26}$ The assay basically involves killing of $\mathrm{T}_{4}$ lymphocytes by HIV. On the basis, that the values evaluated for $50 \%$ effective concentration $\left(\mathrm{EC}_{50}\right)$ against cytopathic effects ranged between 0.17 and $0.20 \mu \mathrm{M}$, the calculated $50 \%$ cell growth inhibitory concentration $\left(\mathrm{IC}_{50}\right)$ was between 94.3 and $92.7 \mu \mathrm{M}$ and the therapeutic index $\mathrm{TI}_{50}(\mathrm{IC} / \mathrm{EC})=454-549$. Thus, AZT-lipid-PFA was judged 'confirmed active'.

\subsubsection{Antiviral activity of AZT-lipid-PFA against HSV type 1 isolates}

The inhibitory potencies of AZT-lipid-PFA, ACV and PFA against HSV-1 isolates are summarised in Table 1. In comparison to ACV the antiviral capacity of AZT-lipid-PFA against the HSVsens KOS multiple passage laboratory strain corresponds nearly to that of ACV but is about 9-fold higher against the highly ACV resistant UL23 KOS-M strain. The replication of clinical HSV cell isolates was inhibited 2 times more effectively than the replication of the HSV laboratory strains (KOS and KOS-M). Surprisingly, AZT-lipid-PFA inhibited the replication of the ACV sensitive pretherapeutic clinical isolates of two recipients of stem cell transplants (HSV-K161, HSV-L177) 4- to 6-fold less effectively as ACV. However, the inhibition of the corresponding sequential ACV resistant isolates (HSV-K143) was 16 times more potent than ACV. Remarkably, the antiviral effect of PFA in comparison to AZT-lipid-PFA was about 25- to 30-fold lower against the HSVsens and HSVres isolates. Due to this very low inhibitory effect the $\mathrm{IC}_{50}$-values of PFA were not further confirmed.

\subsubsection{Antiviral activity of AZT-lipid-PFA against clinical HCMV isolates}

Details of the inhibitory effects of AZT-lipid-PFA, GCV and PFA against sensitive and resistant clinical HCMV isolates were presented at 10th International CMV Workshop in Williamsburg, 2005. The small difference of $\mathrm{IC}_{50}$-values of GCV $\left(\mathrm{IC}_{50}=3.2 \mu \mathrm{M}\right)$ and of AZT-lipid-PFA $\left(\mathrm{IC}_{50}=2.8 \mu \mathrm{M}\right)$ show that both drugs have a comparable antiviral potency against the HCMV-1 sensitive

Table 1

Antiviral activity of acyclovir (ACV), ganciclovir (GCV), Foscarnet (PFA) on replication of different HSV virus strains and clinical HCMV isolates in comparison to AZT-lipid$\mathrm{PFA}$, expressed by the $50 \%$ inhibitory concentration $\left(\mathrm{IC}_{50}\right)$ on viral plaque formation

\begin{tabular}{|c|c|c|c|c|}
\hline \multirow[t]{2}{*}{ Virus strain } & \multicolumn{4}{|c|}{$\mathrm{IC}_{50}(\mu \mathrm{M})$ of antiviral drugs ${ }^{\mathrm{a}}$} \\
\hline & $\mathrm{ACV}$ & GCV & PFA & AZT-lipid-PFA \\
\hline \multicolumn{5}{|l|}{ HSV-1 isolates } \\
\hline KOS & $3.04 \pm 1.65$ & - & 125 & $4.02 \pm 0.81$ \\
\hline KOS-M & $31.20 \pm 1.5$ & - & 112 & $3.39 \pm 0.93$ \\
\hline HSV-K161 sens & $0.58 \pm 0.11$ & ND & ND & $2.27 \pm 1.01$ \\
\hline HSV-K143 res & $75.07 \pm 8.15$ & ND & ND & $4.59 \pm 1.07$ \\
\hline HSV-L177 sens & $0.32 \pm 0.11$ & ND & 64 & $1.92 \pm 0.15$ \\
\hline HSV-L182 res & $9.51 \pm 0.41$ & ND & 46 & $1.87 \pm 0.66$ \\
\hline \multicolumn{5}{|l|}{ HCMV isolates } \\
\hline HCMV-1sens & ND & $3.22 \pm 0.47$ & ND & $2.78 \pm 0.23$ \\
\hline HCMV-3res & ND & $16.40 \pm 5.90$ & $67.50 \pm 8.71$ & $1.18 \pm 0.55$ \\
\hline HCMV-U405cres & ND & ND & $400.12 \pm 69.41$ & $4.29 \pm 2.07$ \\
\hline
\end{tabular}

${ }^{a}$ Results of three individual experiments; ND, not determined. isolates. AZT-lipid-PFA ( $\left.\mathrm{IC}_{50}=1.18 \mu \mathrm{M}\right)$ was about 56-fold more active than PFA $\left(\mathrm{IC}_{50}=67.50 \mu \mathrm{M}\right)$ in cells infected with GCV resistant HCMV-3res and about 93-fold more active in cells infected with HCMV-U405cres isolates which is cross-resistant against GCV and Cidovovir (CDV).

\subsubsection{Possible causes of antiviral activity of AZT-lipid-PFA}

The published AZT-PFA conjugates only report on an optimized anti-HIV activity. The anti-HSV and anti-HCMV activity due to the PFA component was not described. Although these conjugates link AZT and PFA, however, they only show an antiviral effect against HIV and therefore, such conjugates act as a monotherapeutics.

AZT-lipid-PFA seems to be at first time a duplex drug with a broad antiviral spectrum which inhibits the replication of HIV as well as of sensitive and resistant laboratory isolates of HSV and HCMV. Antiviral effects already appear at $\mathrm{IC}_{50}$ ranges of 1.14.6 $\mu \mathrm{M}$. The inhibitory profile of AZT-lipid-PFA against sensitive HSV and HCMV strains correlate with that of ACV and GCV, the drugs that are used as basic therapeutics against HSV and HCMV infections. However, the antiviral effect of AZT-lipid-PFA against resistant HSV and HCMV strains is markedly superior to that of ACV and GCV. Clinical studies have proven PFA as being equivalent to GCV for the treatment of HCMV infections ${ }^{27}$ and superior to vidarabine for the treatment of ACV resistant HSV-strains. ${ }^{28}$ This aspect supports mentioning, that AZT-lipid-PFA shows an up to 30 -fold lower $\mathrm{IC}_{50}$ value in comparison to PFA alone against HSV and even an up to 90 -fold lower $\mathrm{IC}_{50}$ against HCMV. The antiviral activity of the duplex drug, whose PFA component is only $14 \%$ of the total MW, is especially in a resistance setting markly superior to PFA alone. It can be estimated that both components (AZT and PFA) of the duplex drug cause the antiviral effect due to additive or synergistic cooperation, whereby the mechanism is not yet known. A PFA therapy is accompanied by major side effects, therefore every effort to increase the activity of PFA is worth aiming at which could for example be achieved by AZT-lipid-PFA.

The strong antiviral effect of AZT-lipid-PFA is most likely based on the action of several different mechanisms. The duplex drug optimizes an AZT + PFA combination therapy and also acts as a depot for several different inhibitory prodrugs and drug metabolites. The proposed pathway in Fig. 2 suggests that AZT-lipid-PFA can be enzymatically cleaved in several steps to a mixture of lipophilic prodrugs of PFA and AZT (metabolites A and B in Fig. 2), unmodified PFA and AZT besides AZT-5'-monophosphate, with all compounds acting additively or synergistically. For example metabolite A in combination with AZT is strongly synergistically in HT4-6C cells infected with HIV-1. ${ }^{25}$ As the exact metabolism of AZT-lipid-PFA is not yet determined, the supposed pathway shown in Fig. 2 is hypothetical. A major issue in terms of the antiviral effect of AZT-lipid-PFA is the question if metabolic cleavage takes place in- or out-side of the target cell and at what time, in which succession and amounts the different metabolites are formed. These aspects are responsible for gradual differences in the antiviral effects of AZT-lipid-PFA when the $\mathrm{IC}_{50}$-values are determined in different culture media or cell lines. On the other hand, it may be postulated that due to the high variety of the different inhibitory metabolites formed by the AZT-lipid-PFA, the duplex drug would be much less susceptible to resistance than the single drugs.

The structure of AZT-lipid-PFA allows as first ever described complex, especially in contrast to all other previously reported conjugates, an enzymatic pathway that can release AZT-5'-monophosphate without decarboxylation of PFA. In the case that AZT5'-monophosphate is released from AZT-lipid-PFA after cell-uptake, an AZT-resistance based upon a kinase deficiency could be circumvented. If AZT-5'-monophosphate is cleaved outside the cell, the amphipatic AZT-lipid-PFA is transformed into a lipophilic 


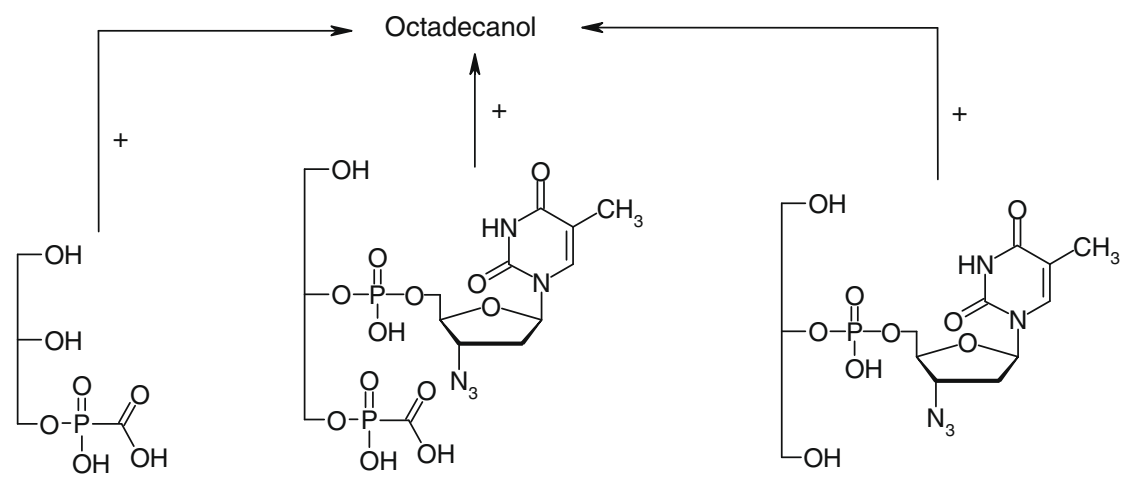

Glycerol-PFA

AZT-glycerol-PFA

Glycerol-AZT
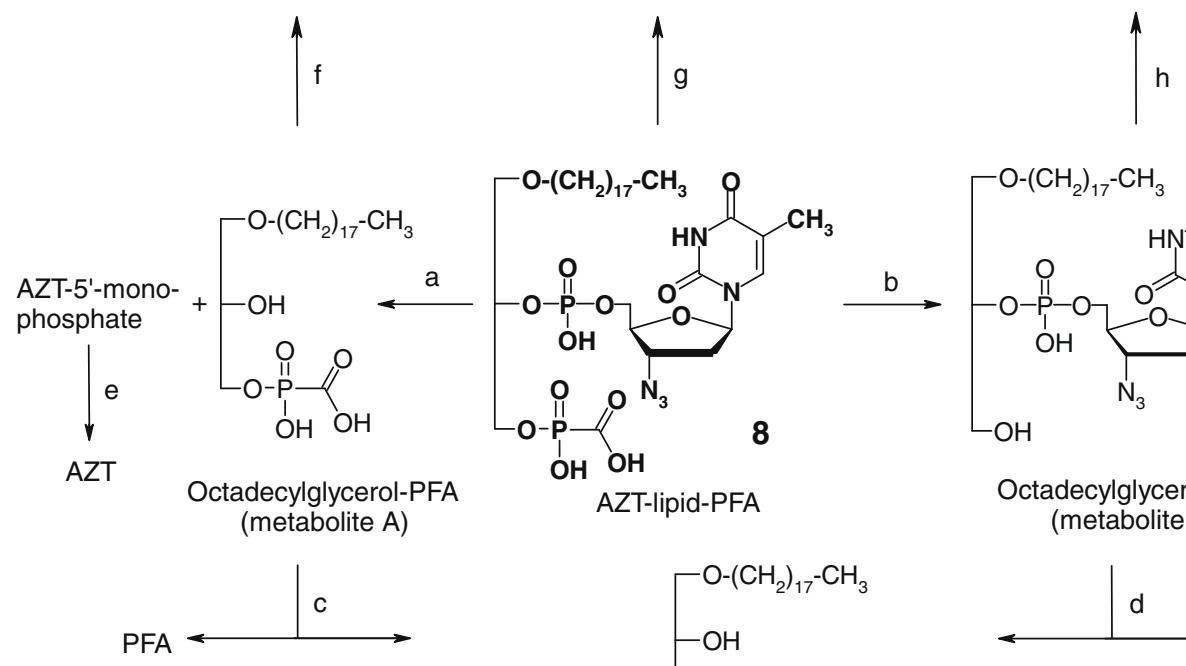

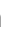

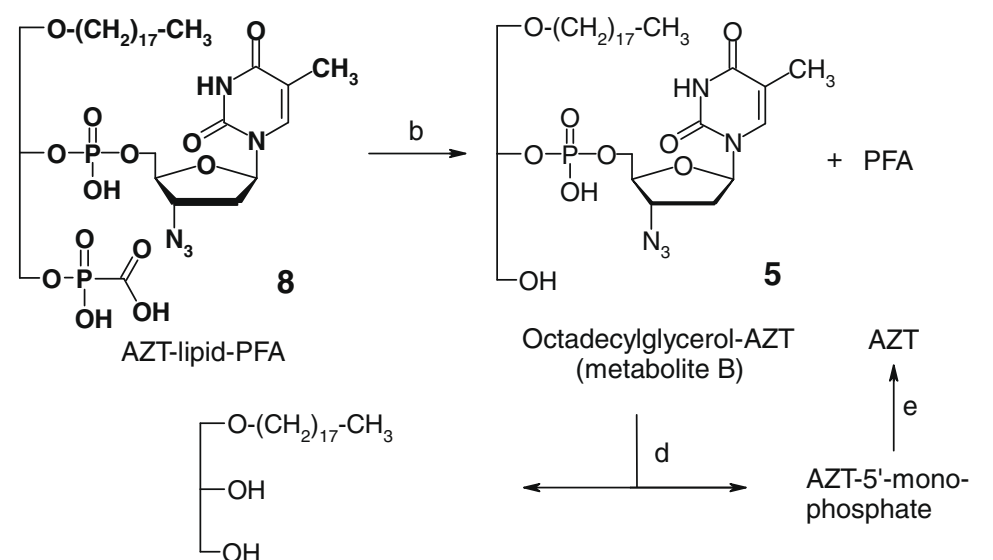

Octadecylglycerol

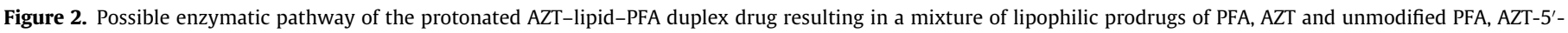
monophosphate and AZT. Depending on the medium the duplex drug and its metabolites either exits in a salt or protonated form.

octadecylglyerol-PFA prodrug (metabolite A, Fig. 2). Due to their increased lipophilicity the PFA prodrugs should permeate the cell membrane even more efficiently than the unaltered duplex drug. In case that the PFA residue is cleaved enzymatically outside the cell, metabolite B, which is a lipophilic prodrug of AZT-5'-monophosphate is formed. This metabolite can presumably easily be taken up by the cell. The lipid-AZT prodrug can target the virus replication cycle in two ways, firstly by inhibiting viral RT by AZT and secondly by inducing the production of defective virus particles by the lipid. ${ }^{29}$ As the inhibitory effect of PFA is mostly depending on the intracellular drug concentration an increased cell-uptake raises the antiviral activity of PFA. In addition, due to the high $\mathrm{IC}_{50}$-values of PFA in comparison to those of AZT, the intracellular PFA concentration seems to be responsible for the occurrence of additive or synergistic effects of PFA and AZT. In case that PFA and AZT occur simultaneously at sufficient concentrations within the cell, AZT resistant mutations can be suppressed by PFAresistant mutations and vice versa. ${ }^{10}$

A preferred site of enzymatic cleavage of AZT-lipid-PFA is the natural phosphodiester bond, which links AZT to the octadecylglycerol residue. The removal of terminal nucleotides, in this case AZT-5'-monophosphate, by exonucleases and/or the primer unblocking reaction by pyrophosphorolysis are well-known mechanisms for the degradation of nucleotide derivatives. Therefore, AZT-5'-monophosphate should easily be cleaved enzymatically from the AZT-lipid-PFA molecule. The remaining metabolite A
(Fig. 2) corresponds to the synthetic octadecylglyerol-PFA prodrug as described previously. ${ }^{23-25}$ The evaluated inhibitory activity of these synthetic PFA prodrugs is 40 - to 140 -fold greater than that of free PFA in cells infected with HIV-1, HSV-1 and HCMV and they are also potent inhibitors of both wild-type HIV-1 $1_{\text {LAI }}$ and most NRTI resistant HIV-1 variants. However, the PFA prodrug was not active against PFA resistance. The antiviral activity of AZT-lipid-PFA against HIV-1, which was evaluated by the $\mathrm{NCI}$, correlated with the described $\mathrm{IC}_{50}$-values of the synthetic octadecylglycerol-PFA prodrugs. As octadecylglycerol-PFA can be released by metabolism of AZT-lipid-PFA, it can be expected that AZT-lipid-PFA is also effective against HIV variants, which are susceptible to the synthetic PFA prodrug. The inhibitory effect of the duplex drug against those HIV variants should be as good as or even better than the synthesized PFA prodrug, because metabolized AZT-lipid-PFA yields several additional AZT metabolites besides octadecylglycerol-PFA. Those metabolites enhance the anti-HIV activity synergistically. ${ }^{25}$

If the enzymatic metabolism of the duplex drug does not initiate with the cleavage of AZT-5'-monophosphate, but with the cleavage of the octadecyl residue (see metabolism f, g, h of Fig. 2) hydrophilic molecules appear. The resulting metabolites are presumably cleaved into PFA + AZT outside of the cells. However, based on the high inhibitory activity of AZT-lipid-PFA the possible breakdown of the octadecyl residue is probably not the first step of the metabolism. 
A comparison of the inhibitory effect of each drug on the basis of the $\mathrm{IC}_{50}$-values, which had been evaluated in the different systems, only provides preliminary data. Based upon this consideration we have compared our $\mathrm{IC}_{50}$-values with those described in the literature. Additive or synergistic effects of AZT-lipid-PFA can indirectly be postulated by comparison of $\mathrm{IC}_{50}$-values of ACV and octadecylglycerol-PFA, which had been previously evaluated for HSV $-1 .{ }^{23}$ The published values show that ACV $\left(\mathrm{IC}_{50}=0.03 \mu \mathrm{M}\right)$ is 30 -fold more active in the used test than the synthetic octadecylglycerol-PFA $\left(\mathrm{IC}_{50}=1.1 \mu \mathrm{M}\right)$. The $\mathrm{IC}_{50}$-values of $\mathrm{ACV}$ in different sensitive HSV-1 isolates, which we have evaluated (see Table 1) are between 0.32 and $3.04 \mu \mathrm{M}$ and therefore only maximally 6 -fold lower than AZT-lipid-PFA $\left(\mathrm{IC}_{50}=1.92-4.02 \mu \mathrm{M}\right)$. The improved HSV activity of AZT-lipid-PFA in comparison to the published octadecylglycerol-PFA indicate that the AZT component contributes to the anti-HSV activity. The contributional effect of AZT is shown even more significantly in the case of resistant HSV-1 isolates, respectively, which had not been evaluated by Hostetler et al. $^{23} \mathrm{IC}_{50}=1.87-4.59 \mu \mathrm{M}$ of AZT-lipid-PFA is maximally 16 times lower than ACV $\left(\mathrm{IC}_{50}=9.51-75.07 \mu \mathrm{M}\right)$. We conclude that the simultaneous release of AZT and octadecylglycerol-PFA from AZT-lipid-PFA supports the PFA-activity additively or synergistically and increases the inhibitory effect. Our assumption is supported by the work of Snoeck et al. ${ }^{15}$ which described additive effects of AZT and PFA against HCMV. The significantly lower $\mathrm{IC}_{50}$-values of AZT-lipid-PFA and its superior antiviral effects in sensitive and resistant virus isolates in comparison to those established show that the duplex drug could have the potential for a new, effective therapeutic alternative to the monotherapy with AZT, ACV, GCA or PFA.

The metabolite $B$, which is released from AZT-lipid-PFA, is the position-isomer compound of the synthetic octadecylglycerol-AZT prodrug previously described ${ }^{22}$ which is 48 times more active than unmodified AZT in reducing HBV replication in 2.2 .15 cells. Structure activity relationships of phospholipid AZT conjugated have shown, that the antiviral activity remains if AZT is linked on position 2 or 3 to the glycerol backbone. ${ }^{29}$ This allows the presumption that AZT-lipid-PFA will also have an antiviral activity against HBV, which might expand the activity spectrum of duplex this drug.

\section{Experimental}

\subsection{General chemistry}

${ }^{1} \mathrm{H}$ and ${ }^{13} \mathrm{C}$ NMR spectra were obtained on a Bruker AC 250 spectrometer at 250 and $62.9 \mathrm{MHz}$ or on a Bruker Avance 400 spectrometer at 400 and $100 \mathrm{MHz}$, respectively. $\mathrm{CDCl}_{3}, \mathrm{DMSO}-\mathrm{d}_{6}$ and $\mathrm{D}_{2} \mathrm{O}$ were used as solvents and $\mathrm{Me}_{4} \mathrm{Si}$ as internal standard. ${ }^{31} \mathrm{P}$ NMR data were obtained on a Bruker Avance 400 spectrometer at $161 \mathrm{MHz}$, using $\mathrm{H}_{3} \mathrm{PO}_{4}$ as the external standard. Mass spectra were measured on a Finnigan TSQ 70 or on a Finnigan MAT 95 instrument. For FAB Mass spectra, all compounds were measured in a NBA-or glycerine matrix. HRMS were measured on a Bruker Apex II FT-ICR instrument. Optical rotations were recorded on a Perkin Elmer 341 polarimeter, using a $10 \mathrm{~cm}$ quartz cell at $\lambda=589 \mathrm{~nm}$ (Na-D-line). Melting points (mp) were measured on a Stuart Scientific SMP3 apparatus and are uncorrected. TLC was performed on pre-coated silica gel plates $60 \mathrm{~F}_{254}(0.25 \mathrm{~mm}$, Merck). The nucleotides-glycerol derivatives and impurities were detected as previously described ${ }^{30}$ using UV-light for visualization and spray reagents as developing agents. The following compounds were synthesized in our laboratory in analogy to previously published methods: salicylchlorophosphite, ${ }^{31}$ 3-octadecyl-sn-glyerol (compound 1 in Fig. 1 ) ${ }^{32}$ (ethoxycarbonyl)phosphoric dichloride, ${ }^{33}$ 4-monomethoxytritylchloride. ${ }^{34}$ 3'-Azido-3'-deoxythymidine (AZT) was extracted from expired drugs. ${ }^{21}$ The synthesized compounds $\mathbf{1}, \mathbf{2}, \mathbf{3}, \mathbf{4}$, and AZT were rigorously dried by repetitive addition of dry pyridine and rotary evaporation before they were further derivatized in pyridine or pyridine containing solutions. All reactions were performed at room temperature if not stated differently. The concentrations of the reaction mixtures, solutions, organic layers and eluted fractions were done in vacuo at a bath temperature of about $45^{\circ} \mathrm{C}$. Preparative column chromatography was carried out at room temperature by flash chromatography on self-packed dry silica gel or equilibrated RP-18 reversed phase (LiChroprep, 40-60 $\mu \mathrm{m}$ ) columns, using mixtures of eluents with increasing amounts of methanol. The eluent was collected in $20 \mathrm{ml}$ fractions and the eluted compounds were identified by TLC.

\subsection{Synthesis of AZT-Lipid-PFA}

\subsubsection{Synthesis of 1-0-4-monomethoxytrityl-3-0-octadecyl-sn- glycerol (2)}

3-O-Octadecyl-sn-glyercol 1 (75 g, $218.6 \mathrm{mmol}$ ) was dissolved in dry pyridine $(380 \mathrm{~g}$ ) and 4-monomethoxytritylchloride (75 g, $240 \mathrm{mmol}$ ) was added. The resulting mixture was stirred under exclusion of moisture for 3 days. After cooling to $5{ }^{\circ} \mathrm{C}$ the precipitate was removed by filtration and washed with cold toluene. The filtrate was combined with the wash solution and concentrated to a sirup which was coevaporated with toluene $(2 \times 100 \mathrm{ml})$ and diluted with petroleum ether $(300 \mathrm{ml})$. The obtained solution was purified on a silica gel column using a petroleum ether/chloroform gradient with increasing parts of chloroform. The pooled fractions of the desired product 2 (UV-, trityl- and glycerol derivative-positive) were concentrated in order to yield $105 \mathrm{~g}$ of $\mathbf{2}(78 \%)$ as colorless sirup, which crystallized by standing openly at room temperature for several days; mp: $48^{\circ} \mathrm{C} ; R_{\mathrm{F}}=0.40$ (chloroform/ petroleum ether $1: 1, \mathrm{v} / \mathrm{v})$; $\mathrm{MS}\left(\mathrm{FAB}^{+}\right), 615.3\left[\mathrm{M}-\mathrm{H}^{+}\right] ;[\alpha]_{\mathrm{D}}^{20}-3.47^{\circ}$ (c 3.57, benzene). Anal. calcd $\left(\mathrm{C}_{41} \mathrm{H}_{60} \mathrm{O}_{4}\right): \mathrm{C}, \mathrm{H} .{ }^{1} \mathrm{H}$ NMR $\left(\mathrm{CDCl}_{3}\right.$, $250 \mathrm{MHz}) ; \delta=0.87\left(\mathrm{t}, 3 \mathrm{H}, J=6.7 \mathrm{~Hz},-\mathrm{CH}_{3}\right), 1.2-1.3(\mathrm{~m}, 30 \mathrm{H}$, $\left.\left(\mathrm{CH}_{2}\right)_{15^{-}}\right), 2.46$, (d, $\left.1 \mathrm{H}, J=4.5 \mathrm{~Hz}, \mathrm{OH}\right), 3.19\left(\mathrm{dd}, 2 \mathrm{H} J_{1}=5.5 \mathrm{~Hz}\right.$, $\left.J_{2}=1.8 \mathrm{~Hz},\left(\mathrm{C}^{\prime \prime}\right) \mathrm{H}_{2}\right), 3.45\left(\mathrm{t}, 2 \mathrm{H}, J=7 \mathrm{~Hz}, \mathrm{O}-\mathrm{CH}_{2}-\left(\mathrm{CH}_{2}\right)_{16}-\mathrm{CH}_{3}\right)$, $3.49\left(\mathrm{~m}, 2 \mathrm{H},\left(\mathrm{C}^{\prime \prime}\right) \mathrm{H}_{2}\right) 3.77\left(\mathrm{~s}, 3 \mathrm{H}\right.$, aryl-O-CH $\left.{ }_{3}\right), 3.94(\mathrm{~m}, 1 \mathrm{H}$, $\left.\left(\mathrm{C} 2^{\prime \prime}\right) \mathrm{H}\right), 6.79-7.46\left(\mathrm{~m}, 14 \mathrm{H}\right.$, aryl-H). ${ }^{13} \mathrm{C}$ NMR $\left(\mathrm{CDCl}_{3}, 62 \mathrm{MHz}\right)$ : $\delta=14.1\left(-\mathrm{CH}_{3}\right), 22.7\left(-\mathrm{CH}_{2}-\mathrm{CH}_{3}\right), 26.1\left(-\mathrm{CH}_{2}-\right), 29.4-29.7$ $\left.\left.\mathrm{CH}_{2}\right)_{15^{-}}\right), 31.9\left(\mathrm{O}-\mathrm{CH}_{2}-\mathrm{CH}_{2}-\left(\mathrm{CH}_{2}\right)_{14^{-}}\right), 55.2$ (phenyl-O- $\left.\mathrm{CH}_{3}\right), 64.6$ (C3"), 69.9 (C2" ), $71.6\left(-\mathrm{O}-\mathrm{CH}_{2}-\left(\mathrm{CH}_{2}\right)_{16^{-}}\right), 72.1\left(\mathrm{C}^{\prime \prime}\right), 86.4(\mathrm{O}-\mathrm{C}-$ phenyl $_{3}$ ), 113.1 (aryl-C), 126.9-130.4 (aryl-C), 135.6 (aryl-C), 144.4 (aryl-C), 158.6 (aryl-C-OMe).

\subsubsection{Synthesis of 1-0-4-monomethoxytrityl-3-0-octadecyl-sn- glycerol-2-hydrogenphosphonate (3)}

A solution of 2 ( $90 \mathrm{~g}, 146 \mathrm{mmol})$ in dry pyridine ( $140 \mathrm{~g}$ ) was diluted by adding dry dioxane $(340 \mathrm{ml})$. Salicylchlorophosphite $(30 \mathrm{~g}$, $148 \mathrm{mmol})$ dissolved in dry dioxane $(140 \mathrm{ml})$ was added and the reaction mixture shaked under exclusion of moisture for $2 \mathrm{~h}$. The reaction was stopped by adding saturated $\mathrm{Na}_{2} \mathrm{CO}_{3}(100 \mathrm{ml})$ and subsequently concentrated to a sirup which was diluted with chloroform $(800 \mathrm{ml})$ and extracted with saturated $\mathrm{Na}_{2} \mathrm{CO}_{3}(400 \mathrm{ml})$. The chloroform phase was concentrated to a sirup which was mixed with ether $(600 \mathrm{ml})$ containing triethylamine $(20 \mathrm{ml})$. This solution was chromatographed on a silica gel column using ether as the first and a chloroform/methanol mixture with increasing parts of methanol as the second eluent. Product containing fractions (UV-, trityl-, and glycerol derivative-positive) were pooled and concentrated to yield $84 \mathrm{~g}(85.0 \%)$ of 3 as sirup. $R_{\mathrm{F}}=0.57$ (chloroform/methanol 8:2 v/v); MS $\left(\mathrm{FAB}^{-}\right) 679.3\left[\mathrm{M}-\mathrm{H}^{-}\right] ;[\alpha]_{\mathrm{D}}^{20}-2.76^{\circ}$ (c 1.42, THF): Anal. calcd $\left(\mathrm{C}_{41} \mathrm{H}_{61} \mathrm{O}{ }_{6} \mathrm{P} \cdot \mathrm{H}_{2} \mathrm{O}\right) \mathrm{C}, \mathrm{H} .{ }^{1} \mathrm{H}$ NMR $\left(\mathrm{CDCl}_{3}\right.$, $250 \mathrm{MHz}): \delta=0.87\left(\mathrm{t}, 3 \mathrm{H}, J=6.7 \mathrm{~Hz},-\mathrm{CH}_{3}\right), 1.2-1.3(\mathrm{~m}, 30 \mathrm{H},-$ $\left.\left(\mathrm{CH}_{2}\right)_{15^{-}}\right), 1.46\left(\mathrm{~m}, 2 \mathrm{H},-\mathrm{CH}_{2}-\right), 3.38\left(\mathrm{~m}, 2 \mathrm{H}, \mathrm{O}-\mathrm{CH}_{2}-(\mathrm{CH})_{16^{-}}\right)$, $3.61\left(\mathrm{~d}, 2 \mathrm{H}, \mathrm{J}=5.4 \mathrm{~Hz},\left(\mathrm{C1}^{\prime \prime}\right) \mathrm{H}_{2}\right) 3.75\left(\mathrm{~s}, 3 \mathrm{H}\right.$, phenyl-O- $\left.\mathrm{CH}_{3}\right), 4.55$ 
$\left(\mathrm{m}, 1 \mathrm{H},\left(\mathrm{C} 2^{\prime \prime}\right) \mathrm{H}\right), 5.73(\mathrm{~s}, 0.5 \mathrm{H}, \mathrm{OPHO}(\mathrm{OH}))$ 6.79-7.46 (m, 14H, aryl$\mathrm{H}), 12.66$ (br, s, $1 \mathrm{H}, \mathrm{PHO}(\mathrm{OH})), 8.28(\mathrm{~s} 0.5 \mathrm{H}, \mathrm{OP}(\mathrm{OH})(\mathrm{OH})) .{ }^{13} \mathrm{C} \mathrm{NMR}$ $\left(\mathrm{CDCl}_{3}, 62.9 \mathrm{MHz}: \delta=14.1\left(-\mathrm{CH}_{3}\right), 22.7\left(-\mathrm{CH}_{2}-\mathrm{CH}_{3}\right), 26.1\left(-\mathrm{CH}_{2}-\right)\right.$, 29.4-29.7 $\left.\left(-\mathrm{CH}_{2}\right)_{15}-\right), 31.9\left(\mathrm{O}-\mathrm{CH}_{2}-\mathrm{CH}_{2}-\left(\mathrm{CH}_{2}\right)_{14}{ }^{-}\right), 55.1$ (phenyl$\left.\mathrm{O}-\mathrm{CH}_{3}\right), 64.6\left(\mathrm{C}^{\prime \prime}\right), 71.2\left(\mathrm{C}^{\prime \prime}\right), 71.5\left(-\mathrm{O}-\mathrm{CH}_{2}-\left(\mathrm{CH}_{2}\right)_{16^{-}}\right), 72.7$ $\left(\mathrm{C}^{\prime \prime}\right), 86.2$ (O-C-phenyl ${ }_{3}$ ), 113.1 (aryl-C), 126.9-130.4 (aryl-C), 135.6 (aryl-C), 144.4 (aryl-C), 158.5 (aryl-C-OMe). ${ }^{31} \mathrm{P} \mathrm{NMR}\left(\mathrm{CDCl}_{3}\right.$, $161 \mathrm{MHz}): \delta=4,1$.

\subsubsection{Synthesis of $3^{\prime}$-azido-3'-deoxythymidylyl-( $\left.5^{\prime} \rightarrow 2-0\right)-3-0$ - octadecyl-sn-glycerol (5)}

Compound 3 (84 g, $123 \mathrm{mmol}$ ) and 3'-azido-3'-deoxythymidine 4 (33 g, $124 \mathrm{mmol}$ ) were dissolved in dry pyridine (260 g). Pivaloyl chloride $(76 \mathrm{ml}, 617 \mathrm{mmol})$ was added and the reaction mixture was stirred under exclusion of moisture for $7 \mathrm{~min}$ before the condensation reaction was stopped by addition of water $(100 \mathrm{ml})$ under cooling. The stirred reaction mixture was oxidized within $2 \mathrm{~h}$ using a solution $(500 \mathrm{ml})$ of iodine $(0.2 \mathrm{M})$ dissolved in THF/pyridine $(18: 1, v / v)$. Then, the solution was decolorized by adding a small amount of solid $\mathrm{NaHSO}_{3}$ and concentrated to a sirup after addition of saturated $\mathrm{Na}_{2} \mathrm{CO}_{3}(60 \mathrm{ml})$, which was coevaporated with toluene $(3 \times 50 \mathrm{ml})$, diluted with chloroform $(600 \mathrm{ml})$ and then extracted with $50 \%$ aqueous $\mathrm{NaHCO}_{3}(200 \mathrm{ml})$. The separated chloroform phase was fractionated on a silica gel column using a chloroform/methanol gradient as eluent. The condensation product protected with the 1-O-4-monomethoxytrityl group was eluted as main product, followed by a small amount of the desired de-tritylated compounds (5), which were collected when the eluent contained more than $50 \%$ methanol. The pooled and concentrated fractions $(62 \mathrm{~g})$ containing the tritylated condensation product were diluted with a mixture $(150 \mathrm{ml})$ of chloroform/methanol $(8: 1, v / v)$, and then de-tritylated using $80 \%$ aqueous acetic acid $(60 \mathrm{ml})$ for $12 \mathrm{~h}$, concentrated to a sirup which was mixed with ether $(300 \mathrm{ml})$ and then re-chromatographed on a silica gel column using a chloroform/methanol gradient. The pooled fraction of the desired product 5 (UV, sugar moiety positive and trityl negative) were concentrated to a foam which was combined with the foam obtained from the first chromatography of the reaction mixture. The total yield of the $\mathbf{5}$ was $63 \mathrm{~g}(75.8 \%)$ which was dried in vacuo over $\mathrm{P}_{4} \mathrm{O}_{10} . \quad R_{\mathrm{F}}=0.75$ (chloroform $/$ methanol $/ 25 \%$ ammoniumhydroxide 20:10:3 v/v/v); $\mathrm{MS}\left(\mathrm{FAB}^{-}\right) 672.2\left[\mathrm{M}-\mathrm{H}^{-}\right]$; $[\alpha]_{\mathrm{D}}^{20} 5.69^{\circ}$ (c 1.16, $\left.\mathrm{H}_{2} \mathrm{O}\right)$; $[\alpha]_{D}^{20}+7.57^{\circ}$ (c 1.17, THF). Anal. calcd $\left(\mathrm{C}_{31} \mathrm{H}_{55} \mathrm{O}_{9} \mathrm{~N}_{5-}\right.$ $\left.\mathrm{NaP} \cdot \mathrm{H}_{2} \mathrm{O}\right) \mathrm{C}$, H. ${ }^{1} \mathrm{H}$ NMR $\left(\mathrm{D}_{2} \mathrm{O}, 400 \mathrm{MHz}\right): \delta=0.88\left(\mathrm{~m}, 3 \mathrm{H},-\mathrm{CH}_{3}\right)$, 1.21-1.38 (m, 32H, $\left.-\left(\mathrm{CH}_{2}\right)_{16^{-}}\right), 1.61\left(\mathrm{~m}, 2 \mathrm{H}, \mathrm{O}-\mathrm{CH}_{2}-\right), 1.94(\mathrm{~m}, 3 \mathrm{H}$, $\left.-\mathrm{CH}_{3}\right), 2.48$ ( $\left.\mathrm{m}, 2 \mathrm{H}, \mathrm{H}-2^{\prime}\right), 3.45-3.81$ ( $\mathrm{m}, 5 \mathrm{H}, \mathrm{H}_{\text {glycerol }}$ ), 3.97-4.41 ( $\mathrm{m}, 4 \mathrm{H}, \mathrm{H}-3^{\prime}, \mathrm{H}-4^{\prime}, \mathrm{H}-5^{\prime}, \mathrm{H}-5^{\prime \prime}$ ), 4.80 (s, br, $-\mathrm{OH}+\mathrm{HDO}$ ), 6.23 (s, br, $\left.1 \mathrm{H}, \mathrm{H}-1^{\prime}\right), 7.76-7.87(\mathrm{~m}, 1 \mathrm{H}, \mathrm{H}-6) .{ }^{13} \mathrm{C}$ NMR $\left(\mathrm{D}_{2} \mathrm{O}, 100 \mathrm{MHz}\right)$ : $\left.\delta=11.9\left(\mathrm{CH}_{3}\right), 13.9\left(-\mathrm{CH}_{2}-\mathrm{CH}_{3}\right), 22.7,26.2,29.3-30.4\left(-\mathrm{CH}_{2}\right)_{15}{ }^{-}\right)$, $32.0\left(\mathrm{O}-\mathrm{CH}_{2}-\mathrm{CH}_{2}-\left(\mathrm{CH}_{2}\right)_{14^{-}}\right), 61.5\left(\mathrm{C3}^{\prime}\right) 62.4\left(\mathrm{C5}^{\prime}\right), 66.5,71.0\left(\mathrm{CH}_{\text {glycerol }}\right)$, $71.7\left(\mathrm{O}-\mathrm{CH}_{2}-\right), 74.4\left(\mathrm{CH}_{\text {glycerol }}\right) 76.1\left(\mathrm{CH}_{\text {glycerol }}\right), 83.7\left(\mathrm{C}^{\prime}\right), 85.5$ (C4'), 110.8 (C5), 119.2, 137.0 (C6), 150.9 (C2), 166.0 (C4). ${ }^{31} \mathrm{P}$ $\operatorname{NMR}\left(\mathrm{D}_{2} \mathrm{O}, 161 \mathrm{MHz}\right): \delta=0.36(\mathrm{O}-\mathrm{PO}(\mathrm{OH})-\mathrm{O}), 18.4(\mathrm{O}-\mathrm{PO}(\mathrm{H})-\mathrm{O})$.

3.2.4. Synthesis of $3^{\prime}$-azido-3'-deoxythymidylyl-( $\left.5^{\prime} \rightarrow 2-0\right)-3-0$ octadecyl-sn-glycerol-1-O-(ethoxycarbonyl)phosphonate (7)

(Ethoxycarbonyl)phosphoric dichloride $6(25 \mathrm{~g}, 130 \mathrm{mmol})$ was dissolved in trimethylphosphate $(75 \mathrm{ml})$ in a $250 \mathrm{ml}$ round-bottomed flask equipped with a drying tube. After addition of $\mathbf{5}$ $(25 \mathrm{~g}, 37 \mathrm{mmol})$ the reaction mixture was stirred for $16 \mathrm{~h}$. The reaction was stopped by pouring the solution slowly into a stirred and cooled solution of saturated aqueous $\mathrm{Na}_{2} \mathrm{CO}_{3}$ (about $225 \mathrm{ml}$ ). The $\mathrm{pH}$ value of the resulting mixture (about $370 \mathrm{ml}$ ) should be kept between 6.5 and 7.0. The obtained solution was halved and purified within two runs by flash chromatography on a RP-18 (40$60 \mu \mathrm{M})$ column $(25 \times 5 \mathrm{~cm})$ using a three step water/methanol elution gradient (1) $50 \%$ methanol (100 ml), (2) linear increasing gra- dient $50 \%$ methanol $(600 \mathrm{ml})$ in the mixing vessel $/ 80 \%$ methanol $(600 \mathrm{ml})$ in the reservoir, and (3) $80 \%$ methanol (1 l). The eluted compounds were identified by TLC (chloroform/methanol/25\% ammonium hydroxide; 20/10/3, v/v/v). The condensation product $7\left(R_{\mathrm{F}}=0.55\right)$ left the column prior to the un-reacted starting material $5\left(R_{\mathrm{F}}=0.75\right)$. The additionally isolated un-reacted starting product $(6.1 \mathrm{~g}, 24 \%$ ) was identical to compound $\mathbf{5}$ and could be reused for a new condensation reaction. Fractions containing the desired compounds were pooled, concentrated and then freeze dried to a colorless solid. The column chromatography purification of the whole reaction mixture yielded $20 \mathrm{~g}(61 \%)$ of $7 \mathrm{mp} 136-140{ }^{\circ} \mathrm{C}$ $R_{\mathrm{F}}=0.55 \quad$ (chloroform/methanol $/ 25 \%$ ammoniumhydroxide 20:10:3, v/v/v); HRMS (ESI ${ }^{-}$) obsd 808.36580, calcd for $\mathrm{C}_{34} \mathrm{H}_{60} \mathrm{~N}_{5} \mathrm{O}_{13} \mathrm{P}_{2} 808.36574\left[\mathrm{M}-\mathrm{H}^{-}\right] ;[\alpha]_{\mathrm{D}}^{20}-1.97^{\circ}$ (c 1.06, water). Anal. calcd $\left(\mathrm{C}_{34} \mathrm{H}_{59} \mathrm{~N}_{5} \mathrm{O}_{13} \mathrm{Na}_{2} \mathrm{P}_{2} \cdot 2 \mathrm{H}_{2} \mathrm{O}\right): \mathrm{C}, \mathrm{H}, \mathrm{N} .{ }^{1} \mathrm{H}$ NMR $(250 \mathrm{MHz}$, $\left.\mathrm{D}_{2} \mathrm{O}\right): \delta=0.83\left(\mathrm{t}, 3 \mathrm{H}, J=6.6 \mathrm{~Hz},-\mathrm{CH}_{3}\right), 1.16-1.31(\mathrm{~m}, 35 \mathrm{H},-$ $\left.\left(\mathrm{CH}_{2}\right)_{16}-\mathrm{CH}_{3}\right), 1.54\left(\mathrm{~m}, 2 \mathrm{H},-\mathrm{CH}_{2}-\right), 1.89\left(\mathrm{~s}, 3 \mathrm{H},-\mathrm{CH}_{3}\right), 2.43(\mathrm{~m}$, $\left.2 \mathrm{H}, \mathrm{H}-2^{\prime}\right), 3.37-3.72\left(\mathrm{~m}, 4 \mathrm{H}, \mathrm{H}_{\text {glycerol }}\right), 4.03-4.41$ (m, 5H, H-5', H5", $\left.\mathrm{H}_{\text {glycerol, }}-\mathrm{O}-\mathrm{CH}_{2}-\right), 4.41-4.56\left(\mathrm{~m}, 2 \mathrm{H}, \mathrm{H}-3^{\prime}, \mathrm{H}-4^{\prime}\right), 6.16(\mathrm{~m}, 1 \mathrm{H}$, $\left.\mathrm{H}-1^{\prime}\right), 7.80(\mathrm{~s}, 1 \mathrm{H}, \mathrm{H}-6) .{ }^{13} \mathrm{C}$ NMR $\left(62.9 \mathrm{MHz}, \mathrm{D}_{2} \mathrm{O}\right): \delta=14.5(-$ $\left.\mathrm{CH}_{3}\right), 16.3\left(-\mathrm{CH}_{3}\right), 16.5\left(-\mathrm{CH}_{3}\right), 25.3,28.7,32.0-32.4\left(-\left(\mathrm{CH}_{2}\right)_{15^{-}}\right)$, 34.6 (C2'), 39.9, 63.8, 63.9, 64.1 (C5'), 67.9, $68.7\left(\mathrm{CH}_{\text {2glycerol }}\right), 73.1$ $\left(\mathrm{CH}_{\text {glycerol }}\right), 74.3\left(\mathrm{O}-\mathrm{CH}_{2}-\right), 76.9\left(\mathrm{CH}_{\text {glycerol }}\right), 86.2\left(\mathrm{C4}^{\prime}\right), 88.1\left(\mathrm{C1}^{\prime}\right)$, 113.4 (C5), 139.8 (C6), 153.5 (C2), 168.6 (C4), 173.3 (PCO), ${ }^{31} \mathrm{P}$ $\operatorname{NMR}\left(161 \mathrm{MHz}, \mathrm{D}_{2} \mathrm{O}\right): \delta=-1.02,-5.02$.

\subsubsection{Synthesis of $3^{\prime}$-azido-3'-deoxythymidylyl-( $\left.5^{\prime} \rightarrow 2-0\right)-3-0$ -} octadecyl-sn-glycerol-1-O-phosphonoformate trisodium salt (8)

A solution of $7(9 \mathrm{~g}, 10 \mathrm{mmol})$ in $1 \mathrm{M} \mathrm{NaOH}(135 \mathrm{ml})$ was stirred for $20 \mathrm{~min}$. Then, the $\mathrm{pH}$ value of the solution was reduced to 8.5 by adding a cation-exchanger resin. The exchanger was removed by filtration and the obtained filtrate freeze dried to yield the colorless product $8(9 \mathrm{~g}, 98 \%)$. mp: $218-220^{\circ} \mathrm{C} \mathrm{dec} R_{\mathrm{F}}=0.14$ (chloroform/methanol/25\% ammoniumhydroxide; 20:10:3, v/v/v); HRMS $\left(\mathrm{ESI}^{-}\right.$) obsd 780.33606, calcd for $\mathrm{C}_{32} \mathrm{H}_{56} \mathrm{~N}_{5} \mathrm{O}_{13} \mathrm{P}_{2} 780.33533$ $\left[\mathrm{M}-\mathrm{H}^{-}\right] ;[\alpha]_{\mathrm{D}}^{20}-2.03^{\circ}$ (c 1.08, water); Anal. calcd $\left(\mathrm{C}_{32} \mathrm{H}_{56} \mathrm{~N}_{5} \mathrm{O}_{13-}\right.$ $\left.\mathrm{Na}_{3} \mathrm{P}_{2} \cdot 4 \mathrm{H}_{2} \mathrm{O}\right): \mathrm{C}, \mathrm{H} .{ }^{1} \mathrm{H}$ NMR $\left(250 \mathrm{MHz}, \mathrm{D}_{2} \mathrm{O}\right): \delta=0.91(\mathrm{t}, 3 \mathrm{H}$, $\left.J=6.6 \mathrm{~Hz},-\mathrm{CH}_{3}\right), 1.22-1.38\left(\mathrm{~m}, 32 \mathrm{H},-\left(\mathrm{CH}_{2}\right)_{16^{-}}\right), 1.63(\mathrm{~m}, 2 \mathrm{H},-$ $\left.\mathrm{CH}_{2}-\right), 1.97\left(\mathrm{~s}, 3 \mathrm{H},-\mathrm{CH}_{3}\right), 2.52\left(\mathrm{~m}, 2 \mathrm{H}, \mathrm{H}-2^{\prime}\right), 3.51-3.81(\mathrm{~m}, 5 \mathrm{H}$, $\left.\mathrm{H}_{\text {glycerol }}\right), 4.03-4.21\left(\mathrm{~m}, 3 \mathrm{H}, \mathrm{H}-4^{\prime} \mathrm{H}-5^{\prime}, \mathrm{H}-5^{\prime \prime}\right), 4.41-4.63(\mathrm{~m}, 1 \mathrm{H}, \mathrm{H}-$ $\left.3^{\prime}\right), 6.15\left(\mathrm{~m}, 1 \mathrm{H}, \mathrm{H}-1^{\prime}\right), 7.82(\mathrm{~s}, 1 \mathrm{H}, \mathrm{H}-6) .{ }^{13} \mathrm{C}$ NMR $(62.9 \mathrm{MHz}$, $\left.\mathrm{D}_{2} \mathrm{O}\right): \delta=14.6\left(-\mathrm{CH}_{3}\right), 16.5\left(-\mathrm{CH}_{3}\right), 25.3,28.7,32.1-32.5$ $\left.\left(\mathrm{CH}_{2}\right)_{14^{-}}\right), 34.6\left(\mathrm{C2}^{\prime}\right), 40.2,64.3\left(\mathrm{C}^{\prime}\right), 67.7\left(\mathrm{CH}_{2 \text { glycerol }}\right), 73.4\left(\mathrm{CH}_{\text {glyc- }}\right.$ erol $), 74.4\left(\mathrm{O}-\mathrm{CH}_{2}-\right), 74.8,77.5\left(\mathrm{CH}_{\text {glycerol }}\right), 88.7\left(\mathrm{C1}^{\prime}\right), 88.9\left(\mathrm{C}^{\prime}\right)$, 113.4 (C5), 139.9 (C6), 154.5 (C2), 168.9 (C4), 178.4 (PCO), 182.0.

${ }^{31} \mathrm{P}$ NMR $\left(161 \mathrm{MHz}, \mathrm{D}_{2} \mathrm{O}\right): \delta=1.33,-3.43$.

\subsection{Virological methods}

\subsubsection{Antiviral drugs}

The stock solution (196 mM) of ganciclovir (GCV, Cymevene ${ }^{\circledR}$ ) contained $543 \mathrm{mg}$ sodium-GCV corresponding to $50 \mathrm{mg} \mathrm{GCV} / \mathrm{ml}$ phosphate buffered saline (PBS). The original stock solution $(80 \mathrm{mM})$ of Foscarnet (PFA, Foscavir $\left.{ }^{\circledR}\right)$ contained $24.0 \mathrm{mg}$ trisodium-Foscarnet $\times 6 \mathrm{H}_{2} \mathrm{O} / \mathrm{ml}$. The stock solution $(111 \mathrm{mM})$ of acyclovir (ACV) contained $27.44 \mathrm{mg}$ sodium-ACV/ml PBS. The stock solution $(100 \mathrm{mM})$ of AZT-lipid-PFA contained $8.4 \mathrm{mg} / \mathrm{ml}$ in PBS.

Further solutions were prepared in Eagles minimal essential medium (MEM) supplemented with $10 \%$ fetal calf serum (FCS), $10,000 \mathrm{U} / \mathrm{ml}$ penicillin $\mathrm{G}, 10 \mathrm{mg} / \mathrm{ml}$ streptomycin sulfate (MEM$10 \%$ FCS) starting from $1 \mathrm{mM} \mathrm{GCV}, 80 \mathrm{mM}$ PFA, $100 \mathrm{mM} \mathrm{ACV}$ and $100 \mathrm{mM}$ AZT-lipid-PFA in MEM -10\% FCS, respectively.

\subsubsection{Cell culture}

HCMV strains were propagated using human foreskin fibroblast (HFF) monolayers in MEM -10\% FCS, which were used between 
passage 15 and 30 for resistance testing and virus propagation. HSV strains were propagated in monolayers of Vero cells in MEM $-10 \%$ FCS. Fibroblast and Vero cells were tested mycoplasma free.

\subsubsection{Viral strains}

Three clinical HCMV strains were used. Strain HCMV-1sens was phenotypically GCV sensitive, while strain HCMV-3res with the UL97 mutation C603W showed GCV resistance. Both strains were derived from a chemosusceptibility trial of the German Society for Virology in 2000. The GCV/CDV cross-resistant HCMV strain U405cres was isolated from a pediatric stem cell transplant recipient. $^{35}$ The ACV sensitive HSV-1 strain KOS was propagated for 3 weeks in the presence of $13 \mu \mathrm{M}$ ACV resulting in the highly ACV resistant KOS-M strain. Sequential pairs of HSV-K and HSV-L strains were isolated from two adult stem cell transplant recipients $\mathrm{K}$ and L. The HSV-K161sens and HSV L177 isolate were both with ACV sensitivity and represent the first pre-treatment viral isolates, whereas the resistant strains (HSV-K161sens and HSV-L177) are longitudinal viral isolates from patients $\mathrm{K}$ and $\mathrm{L}$ with clinically suspected ACV resistance.

\subsubsection{Assays for the determination of the in vitro antiviral activity against HCMV and HSV}

Phenotypic HCMV susceptibility assays were performed using a simplified micro-culture-based plaque reduction assay with cellassociated virus strains, as reported previously. ${ }^{35,36}$ The HSV plaque reduction assay was performed in analogy to published methods. ${ }^{28}$

\section{Acknowledgments}

For the performance of the NMR analysis we thank Dr. Goltz. The excellent technical support of E. Mikeler gratefully acknowledged. The authors thank the National Cancer Institute (Bethesda, USA) for the in vitro HIV testing of AZT-lipid-PFA.

\section{References and notes}

1. Pauwels, R. Antiviral Res. 2006, 71, 77.

2. Simons, C.; Wu, Q; Htar, T. T. Curr. Top. Med. Chem. 2005, 5, 1191.

3. De Clercq, E. Biochem. Pharmacol. 2007, 73, 911.

4. Oversteegen, L.; Shah, M.; Rovini, H. Nat. Rev. Drug Discovery 2007, 6, 951.

5. Tachedjian, G.; Mellors, J.; Bazmi, H.; Birch, C.; Mills, J. J. Virol. 1996, 70, 7171.
6. Kong, X. B.; Zhu, Q. Y.; Ruprecht, R. M.; Watanabe, K. A.; Zeidler, J.; Gold, J. W. M. W.; Polsky, B.; Armstrong, D.; Chou, T. C. Antimicrob. Agents Chemother. 1991, 35, 2003.

7. Smith, R. A.; Anderson, D. J.; Preston, B. D. J. Virol. 2006, 80, 7169.

8. Marchand, B.; Tchesnokov, E. P.; Gotte, M. J. Biol. Chem. 2007, 282, 3337.

9. Goldschmidt, V.; Marquet, R. Int. J. Biochem. Cell Biol. 2004, 36, 1687.

10. Meyer, P. R.; Matsuura, S. E.; Zonarich, D.; Chopra, R. R.; Pendarvis, E.; Bazmi, H. Z.; Mellors, J. W.; Scott, W. A. J. Virol. 2003, 77, 6127.

11. Cruchaga, C.; Ansó, E.; Rouzaut, A.; Martinez-Irujo, J. J. J. Biol. Chem. 2006, 281, 27744.

12. Eriksson, B. F.; Schinazi, R. F. Antimicrob. Agents Chemother. 1989, 33, 663.

13. Koshida, R.; Vrang, L.; Gilljam, G.; Harmenberg, J.; Oberg, B.; Wahren, B. Antimicrob. Agents Chemother. 1989, 33, 778.

14. Palmer, S.; Rasmussen, H.; Harmenberg, J.; Cox, S. Antiviral Chem. Chemother 1996, 7, 14.

15. Snoeck, R.; Andrei, G.; Schols, D.; Balzarini, J.; De Clercq, E. Eur. J. Clin. Microbiol. Infect Dis. 1992, 11, 1144

16. Rosowsky, A.; Saha, J.; Fazely, F.; Koch, J.; Ruprecht, R. M. Biochem. Biophys. Res Commun. 1990, 172, 288.

17. Saha, J.; Ruprecht, R. M.; Rosowsky, A. Nucleosides Nucleotides 1991, 10, 1465

18. Charvet, A. S.; Camplo, M.; Faury, P.; Graciet, J. C.; Mourier, N.; Chermann, J. C.; Kraus, J. L. J. Med. Chem. 1994, 37, 2216.

19. Meier, C.; Aubertin, A. M.; de Monte, M.; Faraj, A.; Sommadossi, J. P.; Perigaud C.; Imbach, J. L.; Gosselin, G. Antiviral Chem. Chemother. 1998, 9, 41.

20. Rosowsky, A.; Fu, H.; Pai, N.; Mellors, J.; Richman, D. D.; Hostetler, K. Y. J. Med Chem. 1997, 40, 2482.

21. Schott, S. Pharm. Ztg 146 2001, 42, 24.

22. Hostetler, K. Y.; Beadle, J. R.; Kini, G. D.; Gardner, M. F.; Wright, K. N.; Wu, T. H. Korba, B. A. Biochem. Pharmacol. 1997, 53, 1815.

23. Hostetler, K. Y.; Kini, G. D.; Beadle, J. R.; Aldern, K. A.; Gardner, M. F.; Border, R.; Kumar, R.; Barshak, L.; Sridhar, C. N.; Wheeler, C. J.; Richman, D. D. Antiviral Res. 1996, 31, 59 .

24. Hammond, J. L · Koontz, D. L · Bazmi, H. Z • Beadle, J. R · Hostetler, S. E · Kini, G. D.; Aldern, K. A.; Richman, D. D.; Hostetler, K. Y.; Mellors, J. W. Antimicrob. Agents Chemother. 2001, 45, 1621.

25. Hostetler, K. Y.; Hammond, J. L.; Kini, G. D.; Hostetler, S. E.; Beadle, J. R.; Aldern, K. A.; Chou, T. C.; Richman, D. D.; Mellors, J. W. Antiviral Chem. Chemother. 2000 11(31), 59.

26. Weislow, O. S.; Kiser, R.; Fine, D. L.; Bader, J.; Shoemaker, R. H.; Boyd, M. R. J. Natl. Cancer Inst. 1989, 81, 577.

27. Balfour, H. H., Jr. N. Engl. J. Med. 1999, 340, 1255.

28. Safrin, S.; Crumpacker, C.; Chatis, P.; Davis, R.; Hafner, R.; Rush, J.; Kessler, H. A.; Landry, B.; Mills, J. N. Engl. J. Med. 1991, 325, 551.

29. Morris-Natschke, S. L.; Ishaq, K. S.; Kucera, L. S. Curr. Pharm. Des. 2003, 9, 1441

30. Schott, H.; Häussler, M. P.; Gowland, P.; Horber, D. H.; Schwendener, R. A Antiviral Chem. Chemother. 1994, 5, 387.

31. Anschütz, R.; Emery, W. O. Liebigs Ann. Chem. 1887, 239, 301.

32. Hirth, G.; Barner, R. Helv. Chim. Acta 1982, 65, 1059.

33. Vaghefi, M. M.; McKernan, P. A.; Robins, R. K. J. Med. Chem. 1986, 29, 1389.

34. Gomberg, M.; Buchler, C. C. J. Am. Chem. Soc. 1923, 45, 207.

35. Eckle, T.; Lang, P.; Prix, L.; Jahn, G.; Klingebiel, T.; Handgretinger, R.; Selle, B.; Niethammer, D.; Hamprecht, K. Bone Marrow Transplant 2002, 30, 433.

36. Prix, L.; Maierl, J.; Jahn, G.; Hamprecht, K. J. Clin. Virol. 1998, 11, 29. 